\title{
Talking about the Knowledge Management and Knowledge Service of University Library
}

\author{
Lili Li \\ Nanyang Institute of Technology, Henan, Nanyang, 473000
}

Keywords: Knowledge Management; Knowledge Service; University Library

\begin{abstract}
As an important place of storage, tradition and knowledge service, university libraries are also faced with tremendous pressure and challenges in the current knowledge-based economy. In the face of the impact of information explosion, changes in users' knowledge needs, and the pressures and challenges faced by libraries Which are also causing the library to constantly innovate the traditional service concept and service mode, integrate the concept of knowledge management and knowledge service in the library service so as to better adapt to the needs of the times and ensure the overall competitiveness of the library, For teachers and students and researchers in colleges and universities to provide better knowledge services. The article analyzes the connotation of knowledge management and knowledge service of university library, analyzes the internal connection between the two and proposes the knowledge service strategy of university library based on knowledge management.
\end{abstract}

\section{The Connotation of College Library Knowledge Management and Knowledge Service}

The development of knowledge management strictly distinguishes librarians and knowledge specialists, and defines the division of labor and responsibilities of librarians. The content of library knowledge management includes explicit knowledge and tacit knowledge management, including knowledge management theory, technology and Methods, rational allocation, use of knowledge, give full play to the various functions of modern libraries, better service to users. The university library should not only manage the traditional knowledge such as books, but also further manage the emerging knowledge types such as databases and network resources and enhance the value-added services of knowledge. On the one hand, the explicit processing of explicit knowledge on the one hand, the establishment of knowledge base, resource base, to enhance the diversity of user choice of knowledge applications; the other hand, to promote the tradition and development of tacit knowledge, training knowledge-based, learning librarian, establishment A stable environment for innovation and application of knowledge resources. Specifically, the knowledge management of university library is reflected in the following characteristics: First, knowledge management as the foundation. Knowledge is an important management content of the library. The library should fully tap its potential, realize the organic combination of knowledge resources and management methods, reasonably apply all kinds of knowledge and give full play to the resource advantages of the library. Second, reflect the core concept of human-centered management. Library activity in the people is an important organization, so the library should focus on people's development, the personal goals and organizational goals unified mobilize the librarian's enthusiasm for work. Knowledge innovation is the most important link in the knowledge management of libraries. Through knowledge management, the internal resources and external resources of the library are closely linked together to promote the interaction and connection between knowledge and information, and finally realize the management goal of knowledge innovation.

The knowledge service of university library takes the collection, organization, analysis and re-ranking of knowledge as the main contents. Librarians should give full play to their professional knowledge of library and information in the service of knowledge to meet the needs of users in obtaining, selecting and using knowledge. Library knowledge service should be "people-oriented" as the core concept, filling and discovering the actual needs of users to meet their knowledge needs, to achieve knowledge innovation, to provide users with personalized, unique, value-added 
knowledge services. The main contents of the knowledge service of university library include four aspects: one is to provide appropriate solutions to the problems provided by users; the other is to excavate and analyze the user's knowledge needs in depth, and then process and organize the information resources to improve the efficiency of knowledge application ; Third is to integrate information technology in knowledge services to achieve knowledge innovation; fourth, through the processing and innovation of literature resources to meet the needs of users, and through personalized service to create value for users, to achieve knowledge of the proliferation of services. The characteristics of the library knowledge service are mainly reflected in the following aspects: First, the knowledge service of the university library to meet the user's knowledge needs as the main objective, accurately grasp the needs of users, the knowledge processing and reorganization, knowledge innovation, to improve the relevance of knowledge services. Secondly, the way of knowledge service of university library embodies personalized and specialized features. According to the user's actual needs and preferences, the library should comprehensively analyze user's problems and environment, form two-way communication with users, design business processes and set up knowledge service platform so as to improve the personalized features of user knowledge services. Finally, the method of knowledge service of university library embodies systematic and intelligent features. Through the advanced information technology library, human resources and information resources are organically integrated, facilitating users to acquire more abundant explicit knowledge and tacit knowledge, and improving the utilization efficiency of information resources.

\section{The Inherent Relationship between Knowledge Management and Knowledge Service in University Library}

Analyzing the connotation of knowledge management and knowledge service in libraries shows that the intrinsic relations between the two are mainly reflected in the following aspects:

First of all, the activities of both are the same. The attributes of university libraries determine the purpose of their knowledge management and how they are presented in order to implement knowledge services, and knowledge management promotes the ability of knowledge services. In turn, the development of knowledge services further enhances the level of knowledge management. Second, the two serve the same. The service targets of university libraries are mainly teachers, students and scientific research workstations. Both knowledge management and knowledge service are based on mining the explicit knowledge resources and tacit knowledge resources obtained by the people, so as to realize resource sharing. Knowledge management will get all kinds of information for effective integration, timely delivery to the user. The knowledge service of university library also provides service and education to user's tradition and exchange of knowledge, so the service object of both is the same. Third, both are supported by modern information technology. Emerging information technologies are directly involved in library knowledge services to enhance user contact with librarians and help librarians efficiently process the information they receive. The development of information technology integrates the virtual information resource system with the actual service, and promotes the development of knowledge service towards individualization and intelligence. Fourthly, both knowledge management and knowledge service put forward higher requirements on the overall quality of librarians. Whether it is knowledge management or knowledge service, libraries need to apply modern management methods to enhance the cultivation of librarians, optimize and allocate talents so that they have the ability to independently access information, process information and convey information, and through new technological means improve the level of knowledge services. Therefore, knowledge management and knowledge services are based on the maximum degree of digging hidden tacit knowledge as the goal. Finally, the knowledge management of university library has promoted the development of knowledge service. Theoretically, the improvement of knowledge management can promote the innovative operation mode of university library, break the traditional service mode, make the library innovate the knowledge service constantly, and finally improve the knowledge service ability of the whole library. To sum up, knowledge management and knowledge service of university library interact with each other and promote each other. Knowledge service is based on knowledge 
management. Knowledge service in turn promotes the development of knowledge management.

\section{The Knowledge Service Strategy of University Library Based on Knowledge Management}

Knowledge management and knowledge service in university library are closely inter-related, so the knowledge service of university library based on knowledge management can be started from the following aspects:

University library to carry out knowledge services must be based on a strong system of data resources, so the university library based on the needs of users to create a rich resource database: First, the construction of a dissertation library. Dissertations are literature resources that reflect the academic characteristics and academic standards of colleges and universities. They are not published in public and have strong academic and academic values. The libraries should pay attention to the construction of dissertations libraries and improve the utilization of dissertations. Second, build an institutional repository. Through the technology platform, the dissertation, work report, experiment data, courseware and multimedia resources of the university scholar are integrated to establish the institutional knowledge base and design the convenient search function so that the user can inquire about the related knowledge. The so-called special features database that is a theme as the core of the establishment of a distinctive document information resources, such as subject characteristics, collection features, local characteristics, etc., in order to provide users with scientific literature information services.

First of all, teaching services for users to carry out knowledge services. For the university library, the teaching user is the key object of knowledge service, and the different levels of teaching in colleges and universities focus on the different points, the application of data and information resources is very rich. Knowledge service personnel in university libraries should fully understand the subject characteristics and teaching level of the university, screen, summarize and sort out the classified materials and intelligence information, and provide higher-value personalized knowledge services for teaching users. For example, a subject for the teaching of course extension materials, teaching materials, etc., but also to provide users with online reference books, teaching reference books, curriculum materials and other electronic resources. Colleges and universities concentrate a large number of academic experts, whose value in scientific research is immeasurable. Academic libraries should provide academic users with personalized knowledge services to help them complete their research projects better. Knowledge service personnel should understand the work habits and working process of scientific researchers, keep close contact with scientific researchers, collect the tacit and explicit knowledge that they generate during work and study, and use knowledge mining, sorting and other techniques Links between knowledge units provide experts and scholars with academic value and forward-looking personalized knowledge services.

The object of knowledge management is not "knowledge" but the person who owns the knowledge. Therefore, the essence of knowledge management belongs to the management of human resources. In the knowledge management, human being is the core role, that is, the main body of knowledge innovation and the carrier of knowledge. Therefore, it is necessary for the university library to set up the discipline librarian team for the knowledge service to the discipline, and establish the subject librarian system so as to better Implementation of embedded knowledge services. The so-called subject librarian is based on subjects, professions, projects and other teaching and scientific research behavior and characteristics of information services librarian to enhance the relevance of knowledge services and support. Under the network and digital environment, interdisciplinary fields and virtual research groups with dynamic changes in research groups and open research groups are constantly emerging. University libraries need to dynamically extract subject librarians from different regions and different disciplines according to project requirements and form a service team. The orientation and objectives of the subject librarian team include tracking the direction of subject development and establishing a document security system; creating a discipline service team to meet the diverse information needs; encouraging users to participate in the interaction and building a ubiquitous library. 


\section{Conclusion}

In short, the development of information technology has promoted the construction and development of digital libraries. Of course, under the guidance of the concept of knowledge management, university libraries should improve the interactive, professional and intelligent knowledge services. Follow-up university libraries to knowledge management philosophy and management model to better integrate into the knowledge services to track and pay attention to the development of knowledge services and cutting-edge university issues, to provide users with higher quality of knowledge services.

\section{References}

[1] Zhang Xiaolin. Toward Knowledge Service: A Look at the Growing Point of Library and Information Service in the New Century [J]. Journal of Library Science in China, 2017, (5): 32-37.

[2] An Yueying. Integration of Knowledge Service Concept in Library under Network Environment - From Information Service to Knowledge Service [J]. Journal of Information, 2012, (6): 77-78.

[3] Han Yu, Yang Baohua. On the Need of Surpassing User Needs of Library Knowledge Service [J]. Library Intelligence Knowledge, 2014, (3): 70-72.

[4] Yu Jianwen, Zhang Jingsheng. New Trends of Library Science in the 21st Century - An Interview with Prof. Wu Weici, Department of Information Management, Peking University [J]. Thesis Library Theory and Practice, 2016, (5): 3-4.

[5] Zhang Ya-nan. Research on Knowledge Services for University Library [J]. Library Research and Research, 2014, (5): 109-112.

[6] Zheng Jia-jia. Exploration of Tacit Knowledge Management Problems in University Libraries [J]. Journal of Library Science, 2014, (8): 31-33. 